\title{
Depressive and post-traumatic stress symptoms following termination of pregnancy in South African women: A longitudinal study measuring the effects of chronic burden, crisis support and resilience
}

\author{
U Subramaney, ${ }^{1} \mathrm{PhD}$; G E Wyatt, ${ }^{2} \mathrm{PhD} ; \mathrm{J}$ K Williams, ${ }^{2} \mathrm{PhD} ;$ M Zhang, ${ }^{2} \mathrm{MS} ; \mathrm{H}$ H Liu, ${ }^{3} \mathrm{PhD} ; \mathbf{D}$ Chin, ${ }^{2} \mathrm{PhD}$ \\ ${ }^{1}$ Department of Psychiatry, School of Clinical Medicine, Faculty of Health Sciences, University of the Witwatersrand, Johannesburg, South Africa \\ ${ }^{2}$ Department of Biobehavioural Sciences, Semel Institute, University of California, Los Angeles (UCLA), USA \\ ${ }^{3}$ Division of Public Health, Department of Medicine and Department of Biostatistics, University of California, Los Angeles (UCLA), USA
}

Corresponding author: U Subramaney (ugasvaree.subramaney@wits.ac.za)

\begin{abstract}
Background. Termination of pregnancy (TOP) remains a controversial issue, regardless of legislation. Access to services as well as psychological effects may vary across the world.

Objectives and methods. To better understand the psychological effects of TOP, this study describes the circumstances of 102 women who underwent a TOP from two socioeconomic sites in Johannesburg, South Africa, one serving women with few economic resources and the other serving women with adequate resources. The relationship between demographic characteristics, resilience and symptoms of posttraumatic stress disorder (PTSD) and depression before, 1 month after and 3 months after the procedure was also examined.

Results. Time since TOP, age, chronic burden, resilience and the interaction of site with religion and site with chronic burden were significant. In addition, site differences were found for religion and chronic burden in predicting depression scores. Women from both sites had significant decreases in depression scores over time. The interaction of time with site was not significant. Higher chronic burden scores correlated with higher depression scores. No variables were significant in the bivariate analysis for PTSD.

Conclusion. Resilience, religion and chronic burden emerge as significant variables in women undergoing a first-trimester TOP, and warrant further assessment in studies of this nature.
\end{abstract}

S Afr Med J 2015;105(11):934-938. DOI:10.7196/SAMJ.2015.v105i11.9394

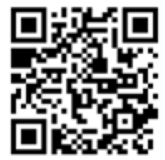

Termination of pregnancy (TOP), the first-trimester outpatient procedure of evacuating the uterus a few hours after administering prostaglandin, is steeped in the context of political, moral and religious controversy. Decisions about TOP are sometimes difficult, and it is likely that many women initially experience symptoms of depression and post-traumatic stress disorder (PTSD) when they choose to terminate a pregnancy. ${ }^{[1]}$

Research regarding the effects of TOP on women's mental health, however, is complex. Symptoms of depression, anxiety and PTSD among adolescents and young women aged $15-25$ years have been documented. ${ }^{[2,3]}$ Associations between TOP and an increased risk of depression, anxiety, suicidal behaviours and substance abuse have also been reported. Reardon et al. ${ }^{[4]}$ studied psychiatric admissions of lowincome women aged 13 - 49 years following TOP and childbirth, and found that TOP was associated with a significantly higher relative risk of psychiatric admission than delivery of a baby, for every time period examined. In another study the degree of adjustment before the pregnancy was found to be a factor contributing to a positive or negative response to TOP, factors associated with a negative emotional adjustment including a history of psychosocial instability, poor or no family ties, few friends and a poor working pattern. ${ }^{[5]}$ While the literature initially supported the notion that TOP has few long-term negative sequelae, ${ }^{[5-7]}$ findings have been mixed. ${ }^{[2-7]}$ Most studies that reported negative mental health sequelae have had methodological limitations. It is important to gain a better understanding of the circumstances and mental health effects of TOP in countries where opportunities to terminate pregnancies have only recently become available.
South African (SA) reproductive health policy and the laws that underwrite it are among the most progressive and comprehensive in the world. ${ }^{[8]}$ Before implementation of the Choice on Termination of Pregnancy (CTOP) Act, ${ }^{[9]}$ only $800-1000$ legal TOPs were performed each year, and many women resorted to illegal and dangerous methods. ${ }^{[8]}$ Within 2 years of the new legislation, over 40000 women accessed abortion services annually. However, gaps in the implementation of reproductive health policies and in service delivery remain and need to be addressed in order to achieve meaningful improvements in women's reproductive health status. ${ }^{[10]}$ Studies have found that women still do not access services owing to lack of information about abortion rights, perceived poor quality of care, and fear of being stigmatised ${ }^{[8,10,11]}$ For example, in one study, $32 \%$ of sexually active women did not know that TOP could be conducted legally; this is especially true of women from rural v. urban areas of the country. ${ }^{[10]}$ Consequently, while the CTOP $\mathrm{Act}^{[9]}$ that replaced the very stringent Abortion and Sterilization Act of $1973^{[12]}$ appears to have had a marked impact on abortion-related mortality, there are few studies that describe the circumstances of TOP. Trueman and Magwentshu ${ }^{[13]}$ emphasise that 16 years after the CTOP Act, negative attitudes and hostility towards abortion have not been eradicated in SA, and the interplay between morals, ethics and legal duties remains controversial. ${ }^{[13]}$

For various reasons, there is lack of enforcement of the law to ensure that the approximately 260 facilities (including private and non-governmental facilities) designated to provide abortion services do so effectively. ${ }^{[8]}$ In addition, women may still be concerned about being judged when they seek an abortion. 
In order to understand the effects of TOP studies of risk and resilience in the context of TOP in SA, as well as the inclusion of factors such as the impact of socioeconomic status and social support, are needed. One such study reported that pre-abortion depression and low self-efficacy predicted postabortion depression. ${ }^{[14]}$ In addition to service provision, there is a dearth of literature on the psychological impact of abortion.

The research reported in this article examines the following multiple distal and proximal factors that may affect the sequelae of TOP: (i) the characteristics and circumstances of women with differing economic profiles who terminate a pregnancy in the first trimester; and (ii) the relationship between demographic factors, resilience, ecosystem and macrosystem factors, and symptoms of depression before TOP (T1) as well as depression and PTSD symptoms 1 month (T2) and 3 months (T3) after TOP.

\section{Methods \\ Procedure}

The study employed a descriptive, analytical approach to a short-term longitudinal study. TOP clinics in SA are available at designated centres in public or private healthcare settings, and by 1997, 292 facilities had been designated nationally. ${ }^{[8]}$ The clinics participating in this study were selected from two different socioeconomic regions in Johannesburg, SA. Site 1 is in an urban area and serves a population of relatively low socioeconomic status. Site 2 is in an affluent suburb of Johannesburg. Women were recruited by responding to flyers at the two clinics. After telephonic screening, those who were eligible consented to take part in the study. At any point in the study, participants who were at high risk in terms of clinical depression and/or suicidality were referred to a community mental health clinic, or to a private mental healthcare practitioner (psychiatrist/psychologist).

\section{Measures}

Participants were personally interviewed at baseline, as well as 1 and 3 months after the procedure. The following demographic information was obtained: age, employment, marital status, language spoken, income and religious affiliation. In addition, the following measures were administered:

- The Chronic Burden Scale, a 21-item selfrating scale measuring difficulties experienced in the past month from a number of stressors (e.g. economic, employment, crime, legal problems). Responses range from 1 (not a problem) to 4 (a major problem). The measure yielded a reliable sum score in a sample of African American,
Latino and Caucasian women (Cronbach's alpha $=0.83)$, with a higher score indicating greater stress burden. ${ }^{[15]}$

- The Crisis Support Scale, measuring social support after a crisis had occurred and rated on a 4-point scale ranging from 0 (never) to 4 (always). ${ }^{[16]}$

- The Connor Davis Risk and Resilience Scale (CD-RISC), a 25-item scale rating items on a 5 -point scale $(0-4)$, with higher scores reflecting greater resilience. ${ }^{[17]}$ The CD-RISC demonstrated good internal consistency and test-retest reliability (Cronbach's alpha $=0.89$ ). There are five subscales: personal competence, social competence, family coherence, social support and personal structure.

- The Beck Depression Inventory (BDI), a 21-item self-rating scale also using a Likert format, assessing depression in mood and thought. ${ }^{[18]}$ As a screening tool for depression, recommended cut-off points are 0 - 9 non-depressed, 10 - 15 mild depression, 16 - 23 moderate depression, and $\geq 24$ severe depression.

- The Impact of Event Scale, revised version (IES-R), a useful tool that assesses the subjective experience of 22 traumatic events in the past week, including intrusive thoughts, re-experiencing and avoidance reactions, each on a severity rating of 0 5. ${ }^{[19]}$ This was administered to monitor symptom changes between $\mathrm{T} 2$ and $\mathrm{T} 3$ together with the BDI.

\section{Statistical analysis}

Statistical analysis was done using SAS version 9.3 (SAS, USA). The two groups were compared on primary outcome measures (BDI for depression, IES-R for PTSD), in addition to clinical and other demographic variables using $\chi^{2}$ tests (for dichotomised variables) and Student's $t$-tests (for continuous measures). Two steps were then undertaken: bivariate analysis between predictors and outcomes for each time point, and a bivariate analysis across the three time points for the depression outcome.

Variables that were significant in step 2 were put in a final model, as were variables that were significant for at least two time points in step 1. For all analyses, statistical significance was set at $p<0.05$ and all tests were two-tailed.

\section{Results Demographic profile}

In total, 124 women were screened, 64 from site 1 and 60 from site 2 . The data from 102 women (51 from each site) who completed all three visits were analysed. Twenty-two women (13 from site 1 and 9 from site 2) were lost to follow-up.

A comparative analysis of the two sites showed that site 1 had more black women and fewer women who were employed outside the home. Those who were employed earned a lower income and were less educated than those at site 2. Also, more women listed an African language as their home language (isiZulu, isiXhosa, Sesotho, Setswana or other) compared with their site 2 counterparts. There were no site differences in terms of marital status and age (Table 1).

\section{Chronic burden, crisis support and CD-RISC scores}

There were no site differences for scores on the chronic burden scale or the crisis support questionnaire scale. Site 2 women had a significantly higher CD-RISC scores (mean 64.9) than site 1 (mean 50.3) ( $p=0.0003)$.
Table 1. Demographic profile of the two sites

\begin{tabular}{|c|c|c|c|}
\hline & Site $1(N=51)$ & Site $2(N=51)$ & $p$-value \\
\hline Age (years), mean (SD) & $29.2(6.5)$ & $27.0(5.2)$ & $t=1.88, p=0.0628$ \\
\hline Race, $n(\%)$ & & & $\chi^{2}<0.0001$ \\
\hline Black & $50(98.0)$ & $35(68.6)$ & \\
\hline Other & $1(2.0)$ & $16(31.4)$ & \\
\hline Marital status, $n(\%)$ & & & 1.0000 \\
\hline Single & $44(86.3)$ & $44(86.3)$ & \\
\hline Married & $7(13.7)$ & $7(13.7)$ & \\
\hline Level of education $\geq$ matric, $n(\%)$ & $26(51.0)$ & $45(88.2)$ & $\chi^{2}<0.0001$ \\
\hline Employed, $n(\%)$ & $31 / 50(62.0)$ & $42 / 50(84.0)$ & $\begin{array}{l}\chi^{2} p=0.0132, \text { Fisher's } \\
\text { exact } p=0.0233\end{array}$ \\
\hline Income $<$ ZAR5 000/month, $n(\%)$ & $31 / 31(100.0)$ & $20 / 42(47.6)$ & $\chi^{2}<0.0001$ \\
\hline Religion Christian, $n(\%)$ & $16 / 47(34.0)$ & $29 / 50(58.0)$ & $\chi^{2} 0.0181$ \\
\hline Black language, $n(\%)$ & $50(98.0)$ & $33 / 50(66.0)$ & $\chi^{2}<0.0001$ \\
\hline
\end{tabular}




\section{Reason for TOP}

Only 22 women $(21.6 \%)$ responded to this question. Of these, 13 (25.5\%) were from site 1 and 9 (17.7\%) from site 2 . There were no significant differences in BDI scores between those who answered this question and those who did not.

\section{Previous TOPs}

For site 1, 14 women reported that this was not their first TOP. Twelve had undergone one other TOP and two had undergone two previous TOPs. For site 2, 12 women reported having undergone previous TOPs. Of these only one had undergone two previous TOPs. There were no significant differences between the BDI scores of women who were having a TOP for the first time v. those who were not.

\section{BDI scores (Tables 2 and 3)}

At baseline, BDI scores were low for both groups. At $\mathrm{T} 2$ and $\mathrm{T} 3$, scores decreased significantly for both groups: for site $1, \mathrm{~T} 1 \mathrm{v}$. T2 mean (standard deviation (SD)) 6.6 (1.03) (95\% confidence interval (CI) 3.22 - 9.99); T2 v. T3 mean 2.43 (3.08) (95\% CI 1.56 3.29), $p<0.0001$; T1 v. T3 mean 9.03 (11.43)
(95\% CI 5.82 - 12.25), $p<0.0001$ ); for site 2 , T1 v. T2 mean 3.6 (9.4) (95\% CI 0.92 - 6.27); T2 v. T3 mean 3.3 (7.65) (95\% CI 6.4 - 9.51); T1 v. T3 mean 7 (11.04) (95\% CI 9.22 13.76), $p<0.0001$.

\section{IES-R scores (Tables 2 and 3)}

Scores were low for both groups at both visits (T2 and T3). The mean score for the IES-R for site 1 was 16 at the initial assessment and 9 at T3. For site 2 the initial mean IES-R score was 19 , and at T3 it was 10 . There were significant decreases in scores between T2 and T3 for both sites (site 1: T2 v. T3 mean (SD) 7.7 (9.98) (95\% CI 4.97 - 10.93), $p<0.0001)$; site 2: T2 v. T3 mean 9.7 (12.11) (95\% CI 10.14 - 15.06), $p<0.0001$ ).

\section{Bivariate analysis: Effect of demographic variables, chronic burden, crisis support and CD- RISC on depression and PTSD}

For site 2 women, religion (belonging to the Christian faith) had a significant impact on depression scores at visits 2 and 3 ( $p=0.0171$ and $p=0.0342$, respectively), as did chronic burden (visit $1 p=0.0079$, visit $2 p=0.0167$ and visit $3 p=0.0002$ ) and CD-RISC (visit 1 $p=0.0378)$. Nothing significant was found for site 1 women.

Table 5 illustrates the bivariate analysis for depression across three time points. Chronic burden as well as resilience (CD-RISC) scores were significantly related to depression across the three time points ( $p=0.0003$ and $p=0.0255$, respectively). None of the predictors was related to PTSD.

Repeated measures analysis (Table 6) Religion, chronic burden and CD-RISC as well as time, site and their interaction term were put in the final model. Time, site and

Table 2. BDI and IES-R scores over time

\begin{tabular}{ccc}
\hline & Site $\mathbf{1}$ & Site 2 \\
\hline BDI scores & & \\
T1 & 11.56 & 13.02 \\
T2 & 4.96 & 9.23 \\
T3 & 2.52 & 5.90 \\
IES-R scores & & \\
T2 & 16.64 & 19.43 \\
T3 & 8.86 & 9.72 \\
& &
\end{tabular}

Table 3. BDI and IES-R scores over time by site

\begin{tabular}{|c|c|c|c|c|c|c|}
\hline & Site $1 \mathrm{~T} 1 \mathrm{v}$. T2 & Site 1 T2 v. T3 & Site 1 T1 v. T3 & Site $2 \mathrm{~T} 1 \mathrm{v}$. T2 & Site $2 \mathrm{~T} 2 \mathrm{v}$. T3 & Site 2 T1 v. T3 \\
\hline \multicolumn{7}{|l|}{ BDI } \\
\hline Mean (SD) & $6.60(1.03)$ & $2.43(3.08)$ & $9.03(11.43)$ & $3.60(9.40)$ & $3.33(7.66)$ & $7.00(11.04)$ \\
\hline $95 \%$ CI & $3.22-9.99$ & $1.56-3.29$ & $5.82-12.25$ & $0.92-6.27$ & $1.18-5.49$ & $3.86-10.14$ \\
\hline$p$-value & 0.0003 & $<0.0001$ & $<0.0001$ & 0.0093 & 0.0031 & $<0.0001$ \\
\hline \multicolumn{7}{|l|}{ IES-R } \\
\hline Mean (SD) & & 7.78 (9.99) & & & $9.71(12.12)$ & \\
\hline $95 \% \mathrm{CI}$ & & $4.97-10.93$ & & & $6.30-13.11$ & \\
\hline$p$-value & & $<0.0001$ & & & $<0.0001$ & \\
\hline
\end{tabular}

Table 4. Bivariate analysis at each time point

\begin{tabular}{|c|c|c|c|c|c|c|c|c|}
\hline & Age & Income & Employed & Religion & Chronic burden & Crisis support & CD-RISC & First TOP \\
\hline BDI 1 (S1) & 0.1594 & 0.0796 & 0.0323 & 0.0571 & 0.2630 & -0.0393 & -0.2091 & 0.0533 \\
\hline BDI 1 (S2) & 0.1114 & 0.4434 & 0.7510 & 0.5804 & 0.0079 & 0.6961 & 0.0378 & 0.5968 \\
\hline BDI 2 (S1) & 0.1127 & 0.0772 & 0.1648 & 0.2417 & 0.2366 & 0.0083 & -0.1191 & 0.0126 \\
\hline BDI 2 (S2) & 0.2595 & 0.4546 & 0.1013 & 0.0171 & 0.0167 & 0.9342 & 0.2378 & 0.9003 \\
\hline BDI 3 (S1) & 0.0779 & 0.0668 & 0.0518 & 0.2153 & 0.3593 & 0.0774 & -0.1904 & -0.0530 \\
\hline BDI 3 (S2) & 0.4363 & 0.5176 & 0.6087 & 0.0342 & 0.0002 & 0.4392 & 0.0578 & 0.5967 \\
\hline IES 2 (S1) & 0.1748 & 0.0412 & 0.0440 & 0.3600 & 0.1359 & 0.2349 & -0.1145 & -0.4280 \\
\hline IES 2 (S2) & 0.0789 & 0.6904 & 0.6636 & 0.9721 & 0.8922 & 0.8147 & 0.2568 & 0.9660 \\
\hline IES 3 (S1) & 0.1788 & 0.0836 & 0.0652 & 0.1261 & 0.1084 & 0.0757 & -0.0970 & -0.0888 \\
\hline IES 3 (S2) & 0.0722 & 0.4178 & 0.5194 & 0.2184 & 0.2780 & 0.9398 & 0.3369 & 0.3749 \\
\hline
\end{tabular}




\begin{tabular}{|c|c|c|}
\hline & Estimate & $p$-value \\
\hline Age & -0.18 & 0.1217 \\
\hline Income & -1.44 & 0.3796 \\
\hline Employment & -1.56 & 0.3296 \\
\hline Religion & 1.93 & 0.1861 \\
\hline Chronic burden & 0.23 & 0.0003 \\
\hline Crisis support & 0.01 & 0.9504 \\
\hline Resilience & -0.08 & 0.0255 \\
\hline First TOP & 0.26 & 0.8699 \\
\hline
\end{tabular}

chronic burden were significantly related to depression. Site 2 had a higher rate of depression reported than site $1(p=0.0007)$. Both sites showed significant decreases in depression over time $(p<0.0001)$. The higher the chronic burden, the higher the depression $(p=0002)$. The interaction of time by site was not significant $(p=0.3263$ ).

As no variables were significant in the bivariate analysis for PTSD, a model for PTSD was not run.

\section{Discussion}

This study examined the initial and shortand moderate-term adjustment of 102 mainly black women who had undergone TOP at one of two clinics, one serving mainly women with low economic resources and the other women of higher socioeconomic status.

In contrast to some findings in the literature, which showed that poor women are more likely to experience negative sequelae after TOP than their financially more secure counterparts, ${ }^{[4]}$ our study found that after a TOP in women with higher income, the higher the levels of chronic burden, the higher the scores were for depressive symptoms, and, not surprisingly, that the higher the resilience, the lower the depression. The availability of support in times of crisis seemed to have no effect on depressive symptoms. This did not hold true for women of lower income. With regard to interventions to ensure that women adjust to the procedure and do not have residual effects that could exacerbate the symptoms of depression, pre- and post-abortion counselling must consider factors such as resilience, social support and economic measures. While not directly examined in this research study, the issue of stigma in obtaining a TOP could have been the reason why only $21.6 \%$ of the women responded to the question 'Reasons for the TOP'.

The value of this study is that it has undertaken careful assessment, via face-to-

Table 6. Final model for depression (repeat measures analysis)

\begin{tabular}{lllll}
\hline Effect & Num. DF & Den. DF & $f$-value & $p$-value \\
\hline Time & 2 & 185 & 33.92 & $<0.0001$ \\
Site & 1 & 90 & 12.44 & 0.0007 \\
Time* site & 2 & 185 & 1.13 & 0.3263 \\
Religion & 1 & 90 & 0.05 & 0.8320 \\
Chronic burden & 1 & 90 & 15.49 & 0.0002 \\
CD-RISC & 1 & 90 & 6.00 & 0.0162 \\
$\begin{array}{l}\text { Num. DF = numerator degrees of freedom; Den. DF }=\text { denominator degrees of freedom; Time*site = interaction between time } \\
\text { and site. }\end{array}$ &
\end{tabular}

face interview, of the demographics in two distinct socioeconomic groups with a focus on race and income. Interesting findings were that across socioeconomic status, scores were generally low for depression. This may reflect transient mood and stress associated with the predicament and decision-making. The findings show that what a woman brings to the experience of abortion can influence how she copes with it. It is also possible that depressive symptoms may have been a result of the procedure itself, i.e. the process of evacuating the uterus in the awake state by manual vacuum aspiration, or the entire experience of terminating a pregnancy, may have led to feelings of depression. Health professionals need to identify some of the economic and life challenges that women report prior to TOP in order better to understand the symptoms, or lack thereof, after the procedure is complete. Service providers may need to ask in-depth questions about previous depressive symptoms to minimise further effects.

\section{Study limitations}

Limitations of the study include the relatively small sample, precluding generalisation to all women in SA. While language (African v. non-African language) was examined, most women spoke English. Ethnicity, cultural differences and rural areas await further study. Religion may play a role in conferring protection against depressive symptoms in women of lower socioeconomic status. However, we did not examine in depth how religious women were, but rather whether they belonged to the Christian faith or not (34\% of women at site 1 and $58 \%$ at site 2 reported themselves to be Christian, with various other religions making up the rest). The interaction between religious belief and socioeconomic burden needs to be studied further.

Finally, while depressive symptoms were selfreported, an objective measure of depression may have been useful to fully understand these findings. The fact that only 22 out of 102 women gave reasons for the TOP limits analysis of this variable as a potential cause for depressive symptoms at baseline. Qualitative measures may provide a richer understanding of decisionmaking in TOP. One such study, reported in 1997, assessed women's experiences of induced abortion under the previous Act. Although limited by small sample size, findings supported the multidimensional nature of the abortion experience, with participants indicating some degree of ambivalence about their experience. The manner in which women responded to the procedure was found to be a joint function of their psychological state and of the social environment in which the abortion occurred. ${ }^{[20]}$

A final limitation is that as the follow-up period in this study was only 3 months, any effects of delayed-onset PTSD symptoms would not have been captured.

\section{Conclusions}

The findings from both clinics suggest that women may not necessarily become depressed or experience trauma in the short or medium term following TOP. Enquiry about social support and resilience factors may assist clinics in improving the experience of women obtaining a TOP. It may be helpful to follow up women later than 3 months after TOP and counsel or refer appropriately. It is suggested that using the ACASI (Audio Interviewer Assisted Computerized Interview, where the questions are read to women to avoid literacy bias) in a larger study would be preferred, so that women would not have to report their reasons to an interviewer. The goal of the changes in legislature regarding TOP was to offer services that were not available to all SA women, and studies like this may aid in understanding how to expand services and ensure that women are more comfortable in seeking them.

Acknowledgements. The authors thank the management and staff of the Boiphaballo women's clinic and the DISA clinic in Johannesburg. The research was supported by the PHODISO training programme in traumatic stress studies (NIH number5 D43 TW007278-04) 


\section{References}

1. Coleman PK, Reardon DC, Strahan T, Cougle JR. The psychology of abortion: A review and suggestions for future research. Psychology and Health 2005;20(2):237-271. [http://dx.doi.org/10.10 80/0887044042000272921]

2. Pope LM, Adler NE, Tschann JM. Postabortion psychological adjustment: Are minors at increased risk? J Adolesc Health 2001;29(1):2-11. [http://dx.doi.org/10.1016/S1054-139X(01)00212-9]

3. Fergusson DM, Horwood LJ, Ridder EM. Abortion in young women and subsequent mental health. J Child Psychol Psychiatry 2006;47(1):16-24. [http://dx.doi.org/10.1111/j.1469-7610.2005.01538.x]

4. Reardon DC, Cougle JR, Rue VM, Shuping MW, Coleman PK, Ney PG. Psychiatric admissions of lowincome women following abortion and childbirth. CMAJ 2003;168(10):1253-1256.

5. Belsey EM. Predictive factors in the emotional response to abortion: King's Termination Study-IV. Soc Sci Med 1977;11(2):71-82. [http://dx.doi.org/10.1016/0037-7856(77)90002-6]

6. Adler NE, David HP, Major BN, Roth SH, Russo NF, Wyatt GE. Psychological responses after abortion. Science 1990;248(4951):41-44. [http://dx.doi.org/10.1126/science.2181664]

7. Cohen L, Roth S. Coping with abortion. J Human Stress 1984;10(3):140-145. [http://dx.doi.org/10.10 80/0097840X.1984.9934968

8. Jewkes R, Rees H. Dramatic decline in abortion related mortality due to the Choice on Termination of Pregnancy Act. S Afr Med J 2005;95(4):250.

. South African Government. Choice on Termination of Pregnancy Act, 1996 (Act No. 92 of 1996). http://www.acts.co.za/choice-on-termination-of-pregnancy-act-1996/ (accessed 10 October 2015). 10. Morroni C, Myer L, Tibarzawa K. Knowledge of the abortion legislation among South African women:
A cross sectional study. Journal of Reproductive Health 2006;3:7. [http://dx.doi.org/10.1186/1742 4755-3-7]

11. Engelbrecht MC, Pelser AJ, Ngwena C, van Rensburg HC. The implementation of the Choice on Termination of Pregnancy Act: Some empirical findings. Curationis 2000;23(2):4-14. [http://dx.doi org/10.4102/curationis.v23i2.624]
12. South African Government. The Abortion and Sterilization Act 2 of 1975 .

3. Trueman KA, Magwentshu M. Abortion in a progressive legal environment: The need for vigilance in protecting and promoting access to safe abortion services in South Africa. Am J Public Health 2013;103(3):397-399. [http://dx.doi.org/10.2105/AJPH.2012.301194]

14. Faure S, Loxton H. Anxiety, depression and self efficacy levels of women undergoing first trimester abortions. S Afr J Psychol 2003;33(1):28-38. [http://dx.doi.org/10.1177/008124630303300104]

15. Gurung RA, Taylor SE, Kemeny M, Meyers H. 'HIV is not my biggest problem': The impact of HIV and chronic burden on depression in women at risk for AIDS. J Soc Clin Psychol 2004;23(4):490-511. [http://dx.doi.org/10.1521//scp.23.4.490.40305]

16. Joseph $S$, Andrews B, Williams R, Yule W. Crisis support and psychiatric symptomatology in adult Joseph S, Andrews B, Williams R, Yule W. Crisis support and psychiatric symptomatology in adult
survivors in adult survivors of the Jupiter cruise ship disaster. Br J Clin Psychol 1992;31(1):63-73. survivors in adult survivors of the Jupiter cruise ship
[http://dx.doi.org/10.1111/j.2044-8260.1992.tb00968.x]

17. Connor KM, Davidson JR. Development of a new resilience scale: The Connor-Davidson Resilience Scale (CD-RISC). Depress Anxiety 2003;18(2):76-82. [http://dx.doi.org/10.1002/da.10113]

18. Beck AT, Beamesderfer A. Assessment of depression: The depression inventory. In: Pichot P, OlivierMartin R, eds. Psychological Measurements in Psychopharmacology. Oxford: S Karger, 1974. [http:// dx.doi.org/10.1159/000395074]

19. Weiss DS, Marmar CL. The Impact of Event Scale - revised. In: Keane JPWTM, ed. Assessing Psychological Trauma and PTSD. New York: Guilford Press, 1996:339-411.

20. Sufla S. Experiences of induced abortion among a group of South African women. S Afr J Psychol 1997;27(4):214-222. [http://dx.doi.org/10.1177/008124639702700403]

Accepted 3 October 2015 